\title{
SPARROWFALL
}

\section{The city never sleeps.}

\section{BY ROBERT DAWSON}

I he city watched with a million eyes, listened with a million ears.

The weather model updated, predicting wet snow that evening. The city moved a concert indoors and phoned the ticket holders. It prepared its fleet of autonomous snowploughs for deployment.

A person - PID chip 02D1AF0E, a permanent resident - picked a McIntosh apple from a tree in an indoor park. The city debited her account and adjusted the tariff by three ten-thousandths of a cent per apple to keep demand stable.

An unchipped person, female, stumbled on a sidewalk just north of the financial district. Her hands trembled, and she seemed to be talking to herself. The city checked radio signals and ascertained that she had no working phone.

Her pink hoodie and faded jeans were worn out and stained by food and perhaps body fluids, but that would become relevant only if the city had to describe her to a human. How people dressed was not its concern.

The city smelt smoke: a circuit in an apartment building had overloaded. The city sent two cleaning robots to extinguish the fire, phoned evacuation orders to 56 residents and put human firefighters on alert.

The unchipped woman passed close to a security camera. The city scanned her face: the whites of her eyes appeared jaundice-dark on the blue channel. Infrared showed elevated temperature and chilled extremities: a human potentially in need of medical attention.

A maintenance robot rolled towards her on the sidewalk. It moved aside, but the woman tripped and crumpled like a rag doll against the mock-marble wall of an office tower.

"Hello?" the city said. "Can you hear me?"

"Yeah," the woman said. "I may be drunk. But I ain't deaf."

"Do you require medical assistance?"

"I ain't hurt. Just gotta pick myself up."

"Is anything else wrong?"

"Plenty, but it's too late for that," she said. "Doctor told me months ago, my liver's going. And I don't qualify for a transplant 'less I quit drinking. So don't bother calling an ambulance." A laugh turned into a cough, then a phlegmy retch.

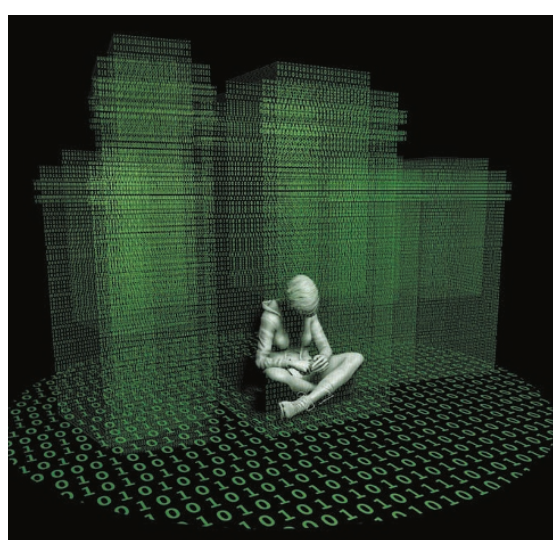

"Basic medical service is free."

"You heard what I said, honey?"

"Is there anything I can do for you?"

"You could put the air vents back. Five years ago there were air vents in the sidewalk, used to be nice and warm." She huddled her arms around her knees.

"Those were removed when the cogeneration system was installed. But if you go northward about 80 metres, there is an alley where you will find the hot-air vent of a server bank."

"Thanks, honey," the woman said. She struggled unsteadily to her feet and stumbled along the sidewalk.

The cleaning robot reported the fire extinguished. The city cancelled the alert. Residents in all but two units were allowed to return.

The unchipped woman turned into the narrow passage. When she reached the vent, she lowered herself carefully to the ground, luxuriating in the warm air.

"Is that satisfactory?" the city asked.

"You still there?"

"Yes. There is a surveillance point in this location to communicate with city workers."

"I used to be a city worker, know that? Back when real men and women had dirt under their nails. I usedta drive a Bobcat, digging trenches for cable ducts. Musta put in a hundred kilometres of them over the years. But now it's all robots. They don't need me any more."

"I do not make large-scale personnel decisions. I'm sorry."

"Sure, I know." She sat there, arms around knees, and hummed tunelessly to herself. After a while she looked up at the surveillance point. "Where's the nearest ladies' room, honey?"
"There's a washroom about five blocks away. Do you want directions?"

"Too far. Hope I'm not going to shock you, but a gal's gotta do what a gal's gotta do." She pulled herself to her feet, limped to the blind end of the alley and squatted behind an abandoned recyclable-plastics bin. A little while later, she returned to her place below the hot air vent, straightening her clothing.

The city had discretion in enforcing bylaws with regard to humans who were ill. It did nothing.

Snow began to fall. The asphalt of the alley slowly turned white, except for a black wet circle below the vent. The sun set: the city turned on 60,000 street lamps in high-traffic areas, and set another 100,000 to proximity operation. After half an hour, it spoke again. "Is there anything I can do for you?"

"You couldn't get me a drink, could you? A li'l bottle of Southern Comfort, maybe, to keep th' cold out?"

"I cannot provide consumer goods without authorization. Should I file a request?"

"Hah! Good luck. Try it if you like."

The city parsed the words carefully and concluded that it had not been requested to take action.

The unchipped woman sat huddled and shivering. The snow was getting heavier.

"Hello? Are you still all right?" There was no answer. The city checked the infrared channel. The woman's skin was losing its warm glow. "Do you need an ambulance?"

The woman sat with her face buried in her knees, rocking almost imperceptibly back and forth.

"Do you need an ambulance?" the city asked again.

She looked up, managed to find the dome of the surveillance point. "Don't you dare." She shivered uncontrollably. "I built you, you bitch!"

"You would be warmer in a hospital," the city said.

There was no response. Over a couple hours the motion stopped, and the infrared channel slowly went dark.

The city scheduled removal of the body for tomorrow's human clean-up crew, marked it 'high priority', and turned its attention to road salting and snow clearance.

Robert Dawson teaches mathematics at Saint Mary's University in Nova Scotia. He has had a PhD from Cambridge for more years than he likes to admit. 